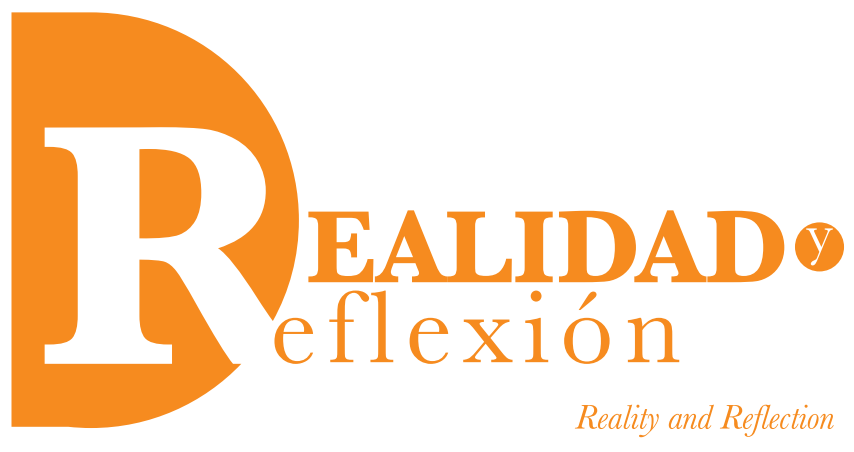

ISSN 1992-6510

Aก̃o $14, \mathrm{~N}^{\circ} 39$

San Salvador, El Salvador, Centroamérica

Revista Semestral

ENERO-JUNIO 2014

YEAR 14, $N^{\circ} 39$,

San Salvador, El Salvador, Central America

SEMESTRAL JOURNAL

JANUARY-JUNE 2014

\title{
Impacto nacional del turismo-industria en el departamento de Usulután
}

\author{
National impact of turism in Usulután
}

\author{
Eduardo Sancho. \\ Licenciado en Sociología, Universidad de El Salvador. \\ Investigador, Instituto ce Ciencia, Tecnología e Innovación \\ de la Universidad Francisco Gavidia. \\ esancho@ufg.edu.sv
}

\section{RESUMEN.}

El surgimiento del turismo en la Región de Occidente y Oriente da vida económica a sectores económicos emergentes en los municipios, abandonados por las políticas de ajuste estructural. Impacta, dinamiza un nuevo entramado de mecanismos económicos y recupera identidad cultural local. Evidencia la caducidad de la administración política territorial del Estado, de 263 municipios, 14 departamentos, de un país pequeño. El departamento de Usulután, granero del país, da sus aportes al replantear tres corredores de desarrollo. Nuestra Tesis es que existen las condiciones para un cambio del modo de producción pre capitalista y del nuevo modelo económico en el país, en varias microregiones, si El Estado desmonta el andamiaje burocrático que impide la producción nacional y apuesta al desarrollo. EL SALVADORUSULUTAN-INDUSTRIA, TURISMO, DESARROLLO RURAL.

\footnotetext{
ABSTRACT

The growth of the tourism in the Region of the West and East gives economic life to emergent economic sectors in the municipalities, left by the policies of structural adjustment. It hits, promotes a new framework of economic mechanisms and recovers local cultural identity. It demonstrates the lapsing of territorial political administration of the State, 263 municipalities, 14 departments, of a small country. The department of Usulután, barn of the country, gives to its contributions when the reframing three routes of development. Our Thesis is that the conditions for a change of the way of capitalist production pre and of the new economic model in the country exist, in several microregions, if the State disassembles the bureaucratic scaffolding that prevents the national production and bets to the development. EL SALVADOR-USULUTANINDUSTRY, TOURISM, RURAL DEVELOPMENT.
} 


\section{Dos epicentros turísticos en las regiones Occidental y Oriental}

Dos epicentros encadenantes surgen en las regiones de Oriente y de Occidente; marcan una ruta nacional de reencuentro con el turismo, en bosque de café, playas, lagos, bahía de Jiquilsico, esteros, cabeceras municipales, zona costera de playa. Surgiendo en cada municipio, en una década, asociaciones empresariales de desarrollo del turismo local, que ilustran la iniciativa de actores locales, comunidades y líderes.

Estas acciones configuran un movimiento socioproductivo local encabezado por los sectores emergentes, capas medias rurales, pequeñas y medianas fincas, dueños de casas urbanas, de playa. Una plataforma física instalada inicial de bosques y playas, que lentamente acumula capital de pequeños y medianos empresarios. Anima a sectores de la agroindustria del café en cooperativas: a la popularización del café especial con cafetines, la catación de nuestro café propio.

Se multiplican las relaciones de producción del turismo con otros sectores, demandan productos industriales, servicios, generando así activación de proveedores, comercio. En espera de grandes inversiones nacionales en Usulután, La Union. Redistribución de ingresos para el lugar turístico. Así, el turismo integra microregiones de los departamentos de Santa Ana, Sonsonante. Usulután,San Miguel, La Unión, en el municipio de Conchagua, y La Libertad. Es el inicio de la democratización económica de pequeñas cuotas de capital en cada departamento.

Con el turismo en cordillera de bosque de café y playa son beneficiados más de
120 municipios. Se convierte en eje de acumulación de capital local, de 52 fines de semana anuales, con dos meses que mueven un mecanismo económico de capitalización local. Se dan grandes y medianas inversiones como el Decamerón, de más de 10 millones, Salinitas y Las veraneras.

La iniciativa en la región de Occidente surge organizada por un grupo de finqueros de café de Apaneca-Ahuachapan; y con el posacuerdo de Paz, 1992-2000, se genera una dinámica local en bosque de café, que desemboca en varias olas en diferentes municipios del país, como Tacuba, Alegría, puerto El Triunfo, Perkín, Tecoluca, ruta nonualca, con el apoyo de la GIZ alemana, se diseñaron planes estratégicos. En el caso de La Libertad, en Santa Tecla y los municipios de Cumbres del Mar, de la cordillera del Bálsamo, se da la ruta del turismo de playa y de bosque de café, encabezados por Jayaque.

Por su geoubicación tiene más ingresos y circulantes monetarios, para pequeños y medianos empresarios de turismo que cuentan con el puerto de Acajutla, con llegada de 6 cruceros al año, que dan inyección de divisas, sumado el turismo de Guatemala y el turismo nacional de fin de semana. Se crea una Ruta de las Flores en la cordillera Lamatepec, que articula varias microregiones de la región. Une Cámara de comercio y asocios. Las cooperativas de café La Majada y Cuzcachapa promueven el café especial. La región de Occidente integra la cordillera Lamatepec con la playa.

La iniciativa nace en la ciudad Alegría, con un grupo asociado de jóvenes para el resguardo ambiental de laguna de Alegría en 1999, hoy en abandono del Estado. Se conjugan intercambios entre 
alcaldes, propietarios de fincas de café, dueños de casas, de Alegría. Puerto El Triunfo, Concepción Batres y la hacienda Chaguantique. La región de Oriente, con una plataforma más deficiente, recibe menor ingreso circulante, su carretera Panamericana estrecha, refleja el abandono y el desinterés de la capital de la República por integrarla al mercado.

Los dos epicentros ecoturísticos en cada región abren la nueva era para un sector estratégico, que se desarrolla desigualmente en las regiones. Desde el año 2000, las regiones se motorizan con el potencial desarrollo de la franja costera y con la franja de bosque de café que genera el turismo. La franja del bosque de café puede evolucionar con mayor rapidez superando la crisis de la roya del café en los próximos 5 años y superando las deudas del pago de interés y las hipotecas.

El nuevo andamiaje productivo que se construye desde el turismo-industria, es favorable a pequeños, medianos industriales y empresarios del agro, y facilita el crecimiento local lentamente desde cero producción y servicios.

\section{Descentralización económica}

No es sino hasta el año 2004 que el Gobierno, reconoce el rol del sector turismo en la vida nacional, creando MINTUR, con el propósito de vender la marca "País impresionante" en el mercado externo, y en período 2009-2014 con la combinación de "Pueblos Vivos", con el mismo mercadeo y la misma promoción. Coincide con el hecho de que del año 2004 al 2013 el GOES intenta reactivar mínimamente las políticas sectoriales, pero sin respaldo de créditos de la banca nacional, ni estatal.
En la década del año 2000 se activa la Asociación o Cámara de Turismo. Se relanza el turismo de playa en la costa de la Cordillera del Bálsamo de café o Cumbres del mar en el año 2005. Cobra iniciativa la Cámara de Turismo. Se relanza el turismo de playa en la costa de la Cordillera del Bálsamo de café o Cumbres del mar.

Nuestra teoría es que se descubre recientemente una vía de desarrollo, turismo y agroindustria, cuyo origen es de la década del 50, los centros turísticos, en los años y 70 que culmina con la construcción del Aeropuerto Internacional.

La evolución da continua activación a la economía local, en un largo periodo de los años 1992-2014, para que no se diga que es por oportunidad coyuntural del mercado. Varios Gobiernos de América Central, Suramérica y el Caribe, dimensionan al turismo como integrador con otros sectores de la economía: Costa Rica, México. España. República Dominicana, Cuba y Perú.

Falta que el Gobierno central considere el turismo, el café, y la industria como vía del desarrollo, en un país sin recursos naturales como petróleo, uranio, que no tenemos para los mercados globales del capitalismo y que es una razón elemental para la producción nacional.

El turismo en el siglo veintiuno reorienta la coordinación intermunicipal y los planes de desarrollo. Se convierte en un mecanismo público privado para el desarrollo económico sectorial. Las alcaldías acompañan a los sectores emergentes, excluidos del mercado interno y externo, excluidos por la banca, y de los Gobiernos centrales, embobados con 
la apertura global, olvidándose de la vida productiva rural, la producción nacional.

Se considera al turismo y a la industria, desde la década del 90, de baja rentabilidad con la agricultura y el café. Y lenta acumulación de ganancias las colocan en la lista negra de alto riesgo para obtener créditos. Esta política de Estado, suprime las políticas sectoriales desde 1990 y elimina la planificación territorial en 1995. Se vendía la propuesta de que el mercado ordenaría la economía y el estado sería un administrador marginal, por lo que se desmantela la vinculación territorial del Estado, que significa un alejamiento del Estado del territorio, de las alcaldías, a quienes se les da formalmente la descentralización.

Con la concentración de un superpoder político de los tres poderes de Estado y económico en la ciudad, la capital de la Republica abandona el sector costero, el sector café bosque, etc. Acepta que la política bancaria cumpla la intención en desmantelar el capital originario agrícola, industria,l y convertir el país en una economía de servicios sin producción nacional, con remesas y con predominio de un modelo consumista desproporcionado, que se refleja en el uso de celulares.

La descapitalización del sector industrial, agroindustrial, granos básicos y sector café se cumple. Profundizada esa crisis interna, la privatización de los sectores públicos estratégicos de la distribución de energía eléctrica, telefonía, la venta de la banca nacional que nacionalizada por el Estado se revende, se suma la dolarización y la poca inversión del capital nacional, que consiste en anular la producción nacional. Y exportar las ganancias máximas.
En el ascenso del turismo naciente sobreviven empresas con baja rentabilidad, con lenta acumulación de capital, con su modesta incidencia que activa la economía local en más de 120 municipios, paralizados y aislados por el mercado.

La reiniciación de una nueva acumulación de capital alrededor de capas medias urbanas y rurales es desde cero. Da un aporte significativo a la recuperación cultural de identidades locales, el patrimonio local tangible e intangible, descuidado, por los Gobiernos y los ciudadanos locales. Este hecho social-económico-cultural es incorporado por los Gobiernos después de los años 2004 y 2009; pero no se respalda a los sectores estratégicos: sector café, sector turismo de playa, de bosque, montaña, lagos. La banca no da respaldo con créditos, ni nacional, ni internacional.

\subsection{La planificación local}

En la región de Oriente, la coordinación municipal se convierte en instrumento clave para consolidar la vía del desarrollo del turismo, industria, agroindustria en forma ordenada, eficiente. Sus actores sueñan con integrar dos microregiones, dos corredores territoriales, que son la bahía de Jiquilisco. y la sierra TecapaChinameca, aunque no era factible por estar desvinculado a la política estatal, esa idea se retoma en el año 2014.

En los esfuerzos por la coordinación estratégica y el ordenamiento territorial de los municipios, se acumulan planes dispersos de cada alcaldía, problema superable con reordenar, recuperar y colocarlos en el rumbo de la visión del desarrollo microregional y departamental. 
Influyen los enfoques de organización, de las ONGS, la cooperación externa y la CDN. Son pioneros SACDEL y FUNDE (Fundación para el Desarrollo), que demuestran capacidad de planificación local, trasmisión de metodologías, apoyados por la cooperación externa que asigna fondos. Son acciones dispersas, acumulándose en 15 planes de turismo dispersos en la bahía de Jiquilisco.

Los planes dedesarrollo local y de municipalismo dan idea de que es posible producir riqueza. Los ejemplos son "Plan de desarrollo turístico del circuito de la bahía de Jiquilisco y Sierra Tecapa Chinameca “, según SACDEL, 2003. A largo plazo coincide con el Plan de Nación de la Comisión Desarrollo Nacional, CDN, del Gobierno, FUNDE, SACDEL, que apoyan al Consejo Departamental de Alcaldes, CDA, con 6 concejos municipales de la bahía de Jiquilisco.

Surgen iniciativas del Estado como La Estrategia Nacional de Desarrollo Local de FISDL, redactada en 1999, sin coordinación estatal, por abandono territorial, ausencia de un Ministerio de Planificación, y queda aislada. Igual se tiene borrador de la Política Nacional de Ordenamiento y Desarrollo Territorial, del MOP, 2007, en Usulután.

En el 2001 surge el Plan de Reconstrucción y Desarrollo del departamento de Usulután, PRISMA, año 2001-2005. UFG, 2003-2007, en la sierra Tecapa Chinameca, con aportes de la Proyección Social de la UFG y estudiantes. Los programas MINEC-FPT, 2010-13 inician la reactivación del camarón, en bahía de Jiquilisco. La STP, 2010-2014.

Surge otra propuesta: La Udel, Unidad de desarrollo local, como nuevo componente para resolver la articulación entre la planificación local, con la coordinación de las inversiones público-privadas de mediano y largo plazos.

Las UDELES, o núcleos de planeamiento local, dependen de la visión del alcalde y su concejo pluripartidista, que serán la clave para entender cuando en su territorio llegan las inversiones pequeñas, medianas o grandes, para no pensar en que lo primero es cobrar impuesto de la inversión. La alcaldía puede cooperar en crear un clima de inversión a las inversiones privadas y estatales, es pues un medidor de la viabilidad. La agenda el FOMILENIO II y las inversiones en Península de San Juan del Gozo.

La inversión privada nacional de los próximos 5 años en la península de San Juan del Gozo, con más de 30 millones de dólares, es decisiva por el impacto de la gran inversión para la ampliación del mercado local y la dinámica Micro regional, con la participación de las alcaldías, el aprovechamiento local de la Inversión Externa Directa, IEP, la formación de capital humano, el clima de inversión, e Infra estructura vial.

A futuro inmediato los concejos pluripartidista pueden acelerar proyectos de impacto, que transformen la relación económica precapitalista en los municipios. Dado que la planificación local no es tan fácil, dada la polarización política y dispersión estatal, ya que si vamos al terreno práctico con un líder, este pregunta a la comunidad sus prioridades, en un cabildo abierto de alcaldía, que es difícil plantear, dado que la opinión o necesidad para la población, sea la calle, la escuela, el poste de electricidad, la vivienda, la seguridad, la microempresa productiva, la sobrevivencia, es prioridad. El techo roto de la escuela, la ausencia de 
profesores, de parvularia, el uniforme para el equipo de futbol, los zapatos para los niños, la leche para los niños, los uniformes para los niños, material didáctico, todas son prioridades. Las respuestas son diversas y surge la dispersión objetiva.

Eso para tomar en cuenta el hecho de que en la economía de sobrevivencia rural, la cultura asistencialista es dominante y el liderazgo local choca con la autogestión productiva de los actores económicos locales, para regenerar el tejido social productivo. Por ello la planificación desde arriba no calza, debe apoyarse en lo que ocurre en el municipio y concretar la articulación.

\section{El corredor social económico de la bahía de Jiquilisco}

El departamento de Usulután, de la región Oriental tiene una dinámica comercial que funciona con una nueva división administrativa de tres corredores, de tres microregiones. Solo la microregión de la bahía de Jiquilisco requiere de una década de coordinación entre alcaldías, para dar el salto a sus rutas turísticas, sus corredores económicos. Igual sucede con sierra TecapaChinameca, sujeta a estudios de UFG -ICTI, entrelos años2004-2010.

La primera señal se da en la alcaldía de Alegría, de 1998-2007, que logra convertirse en atractivo focal de la región de Oriente y a nivel nacional. Ejemplo: el acto con la alcaldía para la celebración en su plaza del 50 aniversario de la Unión Europea, junio del 2007, que organiza la UFG-Alcaldía Alegría con embajadores de Francia, España, Alemania e Italia. Asisten al evento el alcalde de Ciudad Barrios, asocios de cafetaleros de Santiago Maria, Jucuapa y cooperativas de apiarios, convirtiéndose en un punto de encuentro regional, con exposición de mesas de citación de PROCAFE central. Se incorpora el componente de una Pretaza de Excelencia, CENTA regional etc. Se introduce la importancia del café especial. Embalse San Lorenzo-Sesorio, ciudad El Triunfo, Estanzuelas y Nueva Granada van al camino de formar una microregión comercial productiva.

\subsection{Submicroregiones de la bahía de Jiquilisco, Usulután y la bahía La Chepona.}

Las bahías de Jiquilisco y La Chepona tienen impacto nacional en la franja costera, por la producción y el turismo, los deltas de los dos ríos, sus orillas, con el reto de conservar y reproducir recursos del corredor ecológico mesoamericano. $\mathrm{Y}$ su potencial con tierra fértil y materia prima de reproducción en los subsectores: turismo, pesca, cultivos de moluscos, cuilicultura, camarones, coco en la isla Madresal, su Cooperativa el Jobal, de la micro región de la bahía de Jiquilisco, diagnosticados en cada cantón. Pero sin un plan municipal para la reconstrucción del tejido social productivo, faltando el objetivo de construir una plataforma agro industrial de primer piso y de servicios, para estar arriba de la sobrevivencia y del asistencialismo.

La microregión de la bahía de Jiquilisco, que tiene 6 municipios, se puede dividir en dos submicroregiones productivas: la de la bahía de Jiquilisco y la de la bahía La Chepona.

\subsubsection{Submicroregión de la bahía de Jiquilisco.}

Tiene el delta del río Lempa: municipio de Tecoluca, San Vicente, y Jiquilisco-Usulután, municipios de puerto El Triunfo, Jiquilisco, y cabecera departamental, Usulután, con 
plan de ordenamiento territorial. En tierra firme, los asentamientos de comunidades cantonales usan la pesca artesanal para consumo y para el comercio. Casi se ha suprimido la pesca con explosivos. Las comunidades tienen asignadas áreas de reproducción, siembra de arrecifes artificiales y áreas para viveros que deben vigilar. Las áreas de pesca de curvina, bagre, pardo y sardina, en menor cantidad. Microganadería, frutales, hortalizas, arroceras, siembras de caña con productores que desforestan y usan químicos sin control estatal. Jiquilisco es el centro comercial urbano más importante después de la ciudad de Usulután.

La distribución de semillas de maíz frijol del MAG beneficia a 400 manzanas de productores del bajo Lempa, que tiene importancia para pequeños agricultores y es un centro de producción de semilla. La Cooperativa La Canoa, en el futuro será el centro de producción de semillas de frijol y el centro de la distribución nacional. Luego, los trabajadores agrícolas alquilan tierras para sembrar esas semillas, recogen cosechas con la visión de una economía de subsistencia rural. Ese modo de producción se puede cambiar.

Las funciones de los puertos de tierra firme y los muelles de las islas de la bahía Jiquilisco son los puntos de entrada e introducen conexión con la bahía adentro. Se cuenta con la flota de lancheros que transportan turistas, se ocupa para la pesca artesanal, tranporte de mercaderías del comercio y uso privado. Se da la expansión de restaurantes flotantes, paseos a isla Madresal, inversión en infraestructura de hoteles pequeños, playas en las islas, muelles privados, paseos en lancha y en ferris.
El puerto El Triunfo es un complejo agroindustrial abandonado.Tiene tres muelles: uno de pesca artesanal y embarcadero, un muelle de CENDEPESCA y unn muelle privado de las excamaroneras. Es un puerto pionero del desarrollo local de turismo desde 1997, de empresas pequeñas formales e informales, que permite visualizar la expansión de la bahía adentro. Otros puertos son: puerto Parada, que tiene un proyecto de 1.1. millones para el año 2014,Puerto Carao y puerto Ávalos, que son salidas a la bahía adentro desde la tierra firme.

Puerto Parada, municipio de Usulután, con dos cooperativas de pesca artesanal. Puerto Barillas, con servicios turísticos y con yates, hotel, cantón Hacienda La Carrera, con salida a puerto Ávalos, del municipio Jiquilisco y muelles privados. Los puertos menores, con muelles artesanales, tienen un patrón de servicios, puntos de redistribución del comercio bahía adentro, las islas, intercambios de la pesca artesanal y bases de amarre de las lanchas. Pero la gran falla es que la bahía no cuenta con la interconexión marítima de transporte rutinario, por lo que su dinámica es dispersa, lenta y con grandes huecos para resolver le desarrollo que refleje su potencial. A futuro la comunicación interna en la bahía su interconexión, generaría condiciones para un despegue sostenible, que incluya el rol del puerto El Triunfo.

Las reservas forestales protegidas, de tierra firme, y las islas, tienen valor ambiental global como punto del corredor ecológico mesoamericano. Sus principales reservas protegidas son bosques forestales, en bajo resguardo de comunidades cantonales. Chaguantique, con actividad turística y 75 manzanas. El Tercio- Nancuchiname, en área 
de San Marcos Lempa, al lado del margen del bajo Lempa con 1400 manzanas, reserva del mono araña, venado de cola blanca, aves y loras en extinción, con ocho cooperativas de reforma agraria la Normandía.

En área de Sisiguayo, reserva de bosque salado, isla Montecito. Y en el delta del Lempa, tierra de nadie. Otra área es la orilla de tierra firme del bajo Lempa y delta del lado de San Vicente.

Bahía adentro tiene sus recursos naturales materia prima si se organiza la extracción con la reproducción en viveros, corrales etc., de bahía adentro, en islas y rías. Incluye corrales de moluscos, cangrejos, curules, ostras, langostinos, camarones... mejillones, almejas y aun pulpo. Los viveros, corrales de moluscos, en perspectiva lo asumen pequeños grupos familiares, si estos se organizan y reciben la tecnología para tener su red. Son familias dispersas en islas, rías o canales principales, que requieren de educación.

Esta depende de la organización de cada comunidad cantonal de los municipios de Jiquilisco, puerto El Triunfo y de la cabecera departamental de Usulután La isla Madresal, con la Cooperativa heroica El Jobal, produce cocos. No dispone de un soporte tecnológico ni del sistema educativo, para elevar la producción diversificada, alimentaria, de su venta de aceite al mercado local.

Sobre el tema de Aves no se tiene conocimiento local de las aves migratorias. Existen 87 especies de aves; pero no hay guías, ni Policía Forestal para protegerlas, ni observarlas para reproducción. Existe un proyecto del BID a desarrollarse en los próximos años para ese fin.
La península de San Juan es territorio de dos municipios de Jiquilisco y puerto El Triunfo. Por su geoubicación estratégica juega un rol importante para el futuro. Tiene entrada al mar y muelles artesanales; tiene calle desde San Marcos Lempa a Corral de Mulas, pasando por la Canoa y la Isla Montecristo. Sus comunidades activas como Canoa, Canoguita, Mesitas, Lotes, Los Cali. La Tirana; y Chacastera, una cooperativa con 25 socios, ocho socias, muestra del potencial; Lagunita, con la cooperativa de pesca artesanal; y un muelle artesanal: El Jiote, embarcadero para la bahía adentro.

Los caseríos Tates, Los Calix, Las Brisas, La Tirana y varias cooperativas de camarones. Potencial de viveros artesanales de conchas, casco de burro. Tiene además área de reserva, ganado de grupo familiar y siembra de maíz y ajonjolí.

La comunidad cantón Isla Mendez es un modelo de organización, tiene una jurisdicción de protección, siembra de arrecifes en la bahía, vigila los viveros, los territorios del manglar para la reproducción de la vida de peces, moluscos, aves, etc. y evitar la desforestación que cometen las mismas comunidades vecinas. Protección de tortugas de carey, otra especie en extinción, es una cultura de negociación entre compra y venta con unos 150 tortugeros.

Tiene un potencial de playa con 50 kilómetros de dunas. La infraestructura turística, con pistas de aterrizaje de avionetas para interconexión de privados. Es previsible la inversión entre los años 2015-2020, de hoteles para pensionados en retiro, muelle al mar y yates, lo que potenciaría la dinámica turística en la región de Oriente por visitas de cruceros. La 
inversión de más 67 millones para turismo con inversiones medianas y grandes, es un potencial de la infraestructura productiva y del turismo pendiente, y anunciada, pero también requiere del respaldo de los centros educativos y de la transferencia tecnológica.

\subsubsection{Submicroregión de la bahía La Chepona.}

Comprende el delta del Río Grande de San Miguel. Es el sector más oriental de la bahía de Jiquilisco, con municipios de San Dionisio, Concepción Batres, Jucuaran y parte del municipio de Usulután, con las mismas características y potenciales, tierra firme, playas y bahía adentro. El Río Grande tiene $20 \mathrm{~km}$ de orilla con territorio de municipio del Concepción Batres. La preservación del delta de río Grande San Miguel es un proyecto abandonado por el Estado. La UES, realizó estudio de su deterioro, pero no aparece en ningún programa.

Bosque Salado con su granja de camarón es potencial similar al de la de bahía, con turismo de playa, pesca artesanal y agroindustria. Solo con un componente que tiene infratecnológica, laboratorio prelarvas, islas con siembra de coco, turismo rural. Playa del Espino, con sus horatlizas, La Pirraya. Parque Hacienda Nueva, de reserva. Isla Espino con su playa al mar. Isla San Sebastián, delta del Rio Grande. Tiene estero. Jucuaran con sus playas de turismo.

\section{División política administrativa territorial del Estado}

Las dificultades de construir un modelo económico de crecimiento comienza con la división política administrativa territorial del Estado, que cuenta con 262 municipios y
14 departamentos, en un pequeño país. Hay países que tienen una extensión territorial 5 veces u 80 veces más grande que El salvador, como Guatemala, tendrá unos 342 municipios, Honduras, 289 municipios; México tendrá unos 1000. Desproporción comparativa de la dispersión y la atomización administrativa de países descoordinación, descohesión y ausencia del plan de nación acordado. El Estado no logra la integración nacional por la continua atomización de la administración territorial.

Predomina la admiración para el modelo exportador del añil, café de los finales de los siglos XIX y XX, donde se le da el título de municipio por un patrón demográfico. La capital de la república se convierte entonces en una concentración del superpoder político y de los sectores económicos de exportación y excluye a los sectores de la producción nacional, que dependen de la banca nacional.

La tendencia es desvincular el poder de la capital con los territorios. Todo se decide en la capital a favor del modelo exportador exclusivo. Son 262 municipios que no tienen que ver con el crecimiento y el desarrollo territorial de los sectores de la economía la industria, la agroindustria y el turismo.

Y si existiera alguna duda, entes estatal como del ejército nacional, hace caso omiso, y en época de la guerra 1972-1992, utilizó 4 regiones militares para cumplir su misión nacional. La iglesia, utilizó 4 diócesis.

Cabe destacar el estudio de los años 19952000 por la CDN, Comisión del Desarrollo Nacional, con sus miembros pioneros Sandra de Barraza, Roberto Rubio, Francisco De Sola, Salvador Samayoa, David Escobar 
Galindo, Giovanni Berti, Roberto Tercios y David Mena, que dejan varias tesis al GOES. Fue disuelta, en 2009, sin explicación de Estado. Son 15 años disultos de estudio.

La CDN propone dividir el país en 4 regiones, para el desarrollo nacional y aplica el concepto microregional, como criterio de administración. Es el primer intento que se inyecta de avanzada para involucrar a las alcaldías e iniciar el plan de nación participativo y la planificación local.

Iniciado el estudio, es disuelto el Ministerio de Planificación en 1995. El reciente acto de fundación del Estadoy su trespoderes, queda sin rumbo de largo plazo, sujeto a planes quinquenales, que son la discontinuidad del plan quinquenal anterior. La reforma de 1995-2005 en que participó, queda sin efecto en el cambio de Gobierno del año 2000. Pasa inadvertido en el año 1995, cuando FUNDAUNGO plantea reducir gradualmente el número de municipios a 165, en fusiones por distritos.

EI PNUD recupera y plantea la tesis, entre los años 2007-2008 y utiliza alternativas para la gestión del desarrollo humano, dividiendo el territorio interno en 4 regiones, en informe del año 2010.

Este fraccionamiento de administración territorial del Estado no permite integrar país, regiones, ni vías de desarrollo; actualmente es una formalidad legal para el modelo exportador; y la descentralización de las alcaldía es para reencauzar la distribución del poder político de los partidos después de los Acuerdos de Paz. No tiene la vinculación, como mecanismo estatal, para el crecimiento de la producción local. Ese pensamiento, lentamente se supera con la reactivación de la economía rural a nivel nacional, con el apoyo de las alcaldías, célula territorial del Estado, que actúa paralelamente al estado central que desde la capital de la república e ignora la nueva historia económica del sector económico turismo café e industria

\section{Consideraciones}

1. En un país pequeño, con desordenado crecimiento de la población y que tiene como base un modelo demográfico de doble moral, se frena el crecimiento económico. Se frena el bienestar de la comunidad y es difícil la planificación territorial. Es posible introducir por cada una de las microregiones, un cambio del modo de producción y modificar el modelo educativo con actualizar la transferencia tecnológica para las empresas. Con la batalla por recuperar la identidad cultural local, con el patrimonio histórico que recupera el turismo. La señal es que el territorio donde vive la población productiva con sus identidades locales es importante, mientras el mercado es un medio para el crecimiento, mientras que el mercado no es un fin, porque en este caso se promueve el mercantilismo.

2. Las microregiones modifican y dan un nuevo ordenamiento administrativo territorial legal en la bahía de Jiquilisco y en la sierra Tecapa Chinameca. Igual sucede en la región de Occidente, La Libertad. Modifica la visión de líderes y se toma aire oxigenado para evaluar su propio potencial en cada localidad, con la organización microregional para el turismo, la industria y el agro. Este camino de reconstruir la economía 
desde abajo, desde el territorio, requiere de que desde arriba se articulen todos los recursos estatales en función de objetivos nacionalesde respaldo y se logre la facilitación del GOES para fomentar la producción nacional y la ampliación del mercado local interno, y darle así un nuevo rol a las alcaldías.

3. El andamiaje institucional del Estado frena a la industria y la evolución de las pequeñas medianas empresas. Pero surge la nueva ola de fina acumulación del capital originario en cada uno de los municipios de la zona costera y la franja de bosque, pese a la crisis de la roya del café. Se tiene la voluntad de los empresarios para reconstruir la vida del tejido social productivo local.

4. La mínima infraestructura del turismo, inyecta la pequeña inversión local: viveros, hotelitos, casas de campo y artesanías, que es un boom de inversión turística en pequeña y mediana escalas en las playas, en la cordillera del café, la nueva agro industria alrededor del turismo; el comercio en el área rural, con finqueros; el comercio de café al mercado interno, café especial, cafetines, viveros tecnificados de hortalizas, mercado interno de camarones, pesca, curiles, agroalimentos, bosque de café con impacto en los mantos acuíferos, que generan el microclima y bosques que absorben el C02, y son respiraderos.

5. La energía eléctrica se distribuye para viviendas, y no se visualiza que los centros de producción, cooperativas de camarones dislocadas otras la necesitan para elevar la productividad. Se debe incorporar la electrificación desde la línea primaria cercana a centros de turismo en bosque de café sin electricidad, y a los centros de futuros consorcios de cooperativas, socios, agro industria, en la bahía de Jiquilisco, y en privados como centro de hoteles, apartamentos y en aeropuertos privados. El cambio de matriz de distribución y precios del costo de la electricidad, es un cambio y es la primera condición básica como para construir una vía de desarrollo industrial localizada. Siendo la bahía de Jiquilisco parte de los sectores portuarios de la franja costera, como los puertos de Acajutla, occidente; Cutuco, oriente, por el puerto El Triunfo, que en los años 1920-1950 permitía barcos para trasladar café al exterior y otros embarques de importación, indican que se requiere en la bahía de Jiquilisco de una interconexión marítima correspondiente al empuje económico. 6. Modificar la administración del Estado en el sentido de que amplié el criterio de la ley de ordenamiento territorial e incluya el nuevo rol de las alcaldías en el desarrollo local. Debe asignarse nuevas funciones a las microregiones, que marcan una pauta importante en la democracia económica para estimular la producción nacional.

Artículo recibido: 10 de abril de 2014 . Artículo aprobado: 29 de mayo de 2014

\section{Bibliografía}

Alcaldía del municipio de Jiquilisco. Documento "Plan estratégico participativo con énfasis en desarrollo económico”. 2012.

PNUD. Informe sobre el desarrollo humano. 2010-2012.

SACDEL. Documento "Plan de desarrollo turístico del crecimiento de la Bahía de Jiquilisco y Sierra Tecapa Chinameca”. 2004.

Secretaría Técnica de la Presidencia. Documento "Estrategia de desarrollo integral y sostenible de la franja costera marina de El Salvador”. 2013. 